\title{
Indonesian EFL Students' Experiences in a Flipped Classroom
}

\author{
Ika Wahyuni Lestari ${ }^{1, *}$ Anggun Sundari ${ }^{2}$
}

\author{
${ }^{1}$ Universitas Muhammadiyah Yogyakarta, Yogyakarta, Indonesia \\ ${ }^{2}$ Universitas Muhammadiyah Yogyakarta, Yogyakarta, Indonesia \\ * Email: ikawahyuni_11@umy.ac.id
}

\begin{abstract}
A flipped classroom has been widely applied in many educational fields. One of which is in English instruction. Although it has obtained more attention, studies on the flipped classrooms in Indonesian context are rarely found. The present study explored university students' experiences who joined a flipped classroom for the first time. The study discovered the benefits obtained and their difficulties during the flipped classroom. The study employed a qualitative method. Five first-year students who joined a flipped classroom and showed active participation during the flipped classroom learning process were selected. In-depth interviews were conducted to obtain the data. Data were analyzed through thematic coding and member-checked to maintain trustworthiness. The study reported that the students could get flexibility in learning through the implemented flipped classroom and feel more ready for learning. They also perceived that flipped classrooms facilitated discussion. As for the difficulties, the students reported that learning under a flipped classroom was difficult as they could not manage their learning. They also found difficulties due to poor peer collaboration and technical problems. Some recommendations and implications for the improvement in the implementation of flipped classrooms were proposed.
\end{abstract}

\section{Keywords: flipped learning, flipped teaching, flipped classroom, blended learning}

\section{INTRODUCTION}

Blended learning has been widely applied in education, including teacher education. The development of blended learning has raised various models, such as the station-rotation model, individual rotation model, lab-rotation model, and flipped-classroom model [1]. The latter model, the flipped classroom has its uniqueness in that the learning activities are inverted: the input session is done at home through video lectures and material sharing, and the in-class meeting is used to provide better understanding and practices. Therefore, this teaching model can be a new strategy for teachers in conducting the teaching and learning process. Students can also get more exposure to materials and collaborative learning by implementing the flipped classroom model [2]. It can also provide new experiences both for teachers and for students [3]. Many studies have shown its benefits. With this strategy, students could access materials anytime and anywhere [4], [5]. They had flexibility in applying learning styles which suit theirs [6] and providing more opportunity for interactions between teachers and students [5]. The flipped classroom also helped students prepared the materials before the in-class learning [7]. Students could have more effective discussions [7] and better communication among classmates [8].

The authors observed the implementation of the flipped classroom in a teacher training institution in Yogyakarta, Indonesia. The teacher chose the flipped classroom model to focus on enhancing students' listening and speaking skills. The observation showed that although prior studies reported the flipped classroom model's benefits with its implementation, many students presented different responses when joining the course. While some students showed eagerness with the model as indicated by their active participation during the flipped classroom implementation, other students seemed less motivated in joining the program. They showed less participation in the pre-class and in-class activities. This phenomenon showed a gap between findings from prior studies [4], [5], [7], [8] which emphasized students' perceived benefits and the flipped classroom model's actual practice in the specific institution. Given the discrepancy, it is noteworthy to investigate how the students responded to the implemented flipped classroom and how they viewed flipped classroom implementation. Thus, the present study explored students' experiences in a flipped classroom implementation, particularly how they perceived the benefits and the difficulties they faced in joining the flipped classroom.

\section{REVIEW OF LITERATURE}

\subsection{Definitions of a Flipped Classroom}

Many scholars defined the flipped classroom. A flipped classroom is the opposite of a traditional classroom [8]. In a traditional classroom, the learning process occurs in a class and the follow-up activities after the input session are conducted at home. In a flipped classroom, the input session is done in advance before the in-class meeting, while in the inclass meeting, follow-up activities are conducted for better understanding. The flipped classroom is a teaching model that applies interactive in-class activities and personal online 
activities [9]. The personal online activities done beforehand are aimed to prepare students with materials to learn inside the classroom [3]. Students can watch video lectures [5], read materials in advance, do quizzes, or analyze cases [3]. The present study operationally defined flipped classroom as a learning model that applies two sessions: 1) activities before the in-class activities for input session and 2) in-class activities

\subsection{Characteristics of a Flipped Classroom}

A flipped classroom's main characteristics lie in the inversion compared to the traditional one. Unlike a traditional classroom, which starts its learning in its in-class meeting, the flipped classroom starts the learning before the in-class meeting. A flipped classroom is characterized by pre-class activities, in-class activities, and assessment [10]. The preclass activities are done by providing materials and other related resources to students who are accessible online. Students can be required to watch video lectures [5] or read materials cases [3]. Students can be involved in a more active and engaged learning environment in in-class learning through collaborative activities such as discussions. They are also allowed to understand the materials in advance through the pre-class activities. In the flipped classroom assessment, measuring students' understanding and achievement can be done in various ways, such as through discussion forums, online quizzes, wikis, and other platforms in the pre-class or in-class activities.

\subsection{Benefits of a Flipped Classroom}

With a flipped classroom, students can benefit from its implementation. It enables students to access materials anytime and anywhere. [4] Since the model applies blended learning, materials and learning resources can be uploaded online and reduce students' reliance on teachers' explanations as sources of knowledge [5]. With the accessibility of the materials and learning resources, students can also manage and control their learning. With the materials learned beforehand, students can also feel more confident when joining the in-class learning [7]. Another benefit students can obtain through the implementation of a flipped classroom is in terms of engagement. Peer engagement can be facilitated in a flipped classroom since students have more time and opportunity to discuss [8]. They can ask questions to their peers for better understanding. Therefore, in-class meetings can be used efficiently and open more significant opportunity to lead to better achievement [11]. Besides learning from their peers, they can also train themselves to be their learning manager, so learning becomes more effective [4].

\subsection{Difficulties in a Flipped Classroom}

The template is used to format a paper and style. Previous studies reported some challenges students faced during their participation in the flipped classroom. A study by [3] reported that students were overwhelmed with the preparation in the pre-class activities they had to do, such as learning or reading materials or watching video lectures. When students do not get used to doing autonomous learning in the flipped classroom, they might be overwhelmed. Besides independent learning in the pre-class activities, flipped classroom implementation also relies heavily on technology and internet access. Students who are not tech-savvy might have problems in learning under flipped classroom [5]. It will also be a problem if technological tools such as smartphones or computers are not available to support students' learning [12]. Students are encouraged to collaborate and participate actively during the teaching and learning process in in-class activities. Another study by [13] reported that students who did not favor active learning and collaborative learning might deal with problems when they learned in a flipped classroom. For better implementation of a flipped classroom, future flippers need to put these findings into consideration

\subsection{Flipped Classroom in the Context of the Study}

In the present study, the flipped classroom was conducted in an English course offered to the first-year students, focusing on listening and speaking skills. The flipped classroom was conducted at an English Language Education Department of a teacher training institution in Yogyakarta, Indonesia. The students enrolled in the course had to attend sixteen meetings in which the meetings were conducted both online and offline. The whole session had four main topics to discuss. In each topic's initial meeting, the students must learn materials beforehand through videos and materials uploaded in the learning management system. These activities became the preclass activities which characterized flipped classroom. In the following meeting, the in-class meeting, the students had some discussion and practices to measure and complement their understanding of the materials. They did role-playing, small group discussions, quizzes, and many other activities to understand.

\section{METHOD}

\subsection{Design}

The present study aims to explore first-year students' experiences with the implementation of a flipped classroom. A qualitative study was employed to obtain their perception and experiences on the benefits and challenges of implementing the flipped classroom to understand the experience. A qualitative study was suitably applied when participants were asked to share their experiences on a phenomenon [14].

\subsection{Setting}

The study was conducted in the English language department of a university in Yogyakarta, Indonesia. The university has been implementing blended learning and providing a learning management system. Some courses in the department also apply a flipped classroom model. The course was conducted in the academic year 2019/2020. The data were collected in June 2020 at the end of the program. 


\subsection{Participants}

Since not all students had experiences attending a flipped classroom, they were purposefully selected to ensure before joining a flipped classroom. Participants should be selected based on criteria which meet the need of the study [15]. Five students were selected as the participants of the study. They were selected based on active participation in the pre-class and in the in-class activities, as seen from their in-class attendance and online participation. They attended at least $75 \%$ of the total meeting. This criterion was set to ensure that they attended more meetings so that they could share their experiences. The teacher's recommendation on the potential participant candidates was also taken into account in selecting the participants. The names of the participants were changed into pseudonyms to maintain their privacy.

\subsection{Data Collection}

Data were collected through a one-on-one interview equipped with an interview protocol. The participants were asked to share their experiences based on the questions, which were the benefits and the challenges when joining a flipped classroom. Several steps in collecting data were gone through. First, one of the authors contacted the potential candidates that met the criteria and asked for their consent to participate in the study. When the participants had consented to be the participants, the author interviewed the participants one by one based on the agreed schedule. The interview was audiorecorded under the participants' consent. The interview was conducted in the Indonesian language as the first language of both the interviewer and the interviewees

\subsection{Data Analysis}

The data from the interview was transcribed verbatim and coded. Thematic analysis was used in coding the themes obtained from the interviews. The authors' member-checked the findings by returning the interview transcript to the participants to maintain the findings' trustworthiness. The themes were also coded based on the agreement of the two authors

\section{RESULTS AND DISCUSSIONS}

This section explains the study results, which consist of the benefits and difficulties of implementing a flipped classroom.

\subsection{Benefits of the Implementation of a Flipped Classroom}

The study showed that the participants perceived the benefits of the implementation of a flipped classroom. Three themes on the benefits emerged, i.e., enabling flexibility in learning, facilitating discussions, and increasing students' readiness.

\subsubsection{Enabling flexibility in learning}

The implemented flipped classroom offered various forms of flexibility in learning, including the flexibility of time and learning places. Andrew said, "[it is] freer, at home we can learn while doing other things." Similarly, Cindy stated, "I can arrange it myself, so I want to learn anytime, it is not scheduled, eh, I mean there is no standard, it's up to me, whenever I want it." The excerpts indicated that the participants perceived that they could be flexible in learning within the flipped classroom. They could decide the time where they were comfortable to study while doing other activities. Besides the flexibility of time and place of learning, the participants also viewed that the flipped classroom offered flexibility on learning styles. Bella stated, “..so we can also arrange the situation in a way that we want". Dara also said, "For me personally, I am more absorbed in my learning if that is material." The participants showed that they could find learning strategies that match their preference and style. With the preferred learning strategies, they could learn more effectively.

Finally, the participants indicated that they got flexibility in accessing materials with the flipped classroom's implementation. "Students do not need to go to class or campus because learning can be done at home, so can the material be accessed at that time even though they are sick" (Andrew). Cindy also added, "The time is flexible so that I can access the material anytime." In the flipped classroom, the learning activities start even when in-class learning has not been conducted as there are pre-class learning activities. One of which is reading materials. Materials are uploaded to the learning management system so that students can access them anytime.

The excerpts of the interview showed that the students perceived flexibility with the implementation of a flipped classroom. By joining the flipped classroom, they could manage their learning by choosing the time and place. They can also do other errands while still being able to get knowledge. The students are equipped with accessible materials anytime and anywhere through the learning management system. Therefore, they do not only rely on their teacher's explanation to learn the materials. Similar findings in some prior studies [2], [4], [5], [7] collaborated with the present study's findings highlighting the flexibility a flipped classroom offered in terms of time, place, and learning sources. Within a flipped classroom, the students reported that they could manage their learning, depending on their learning style. Strayer also found that students could select learning styles that match their learning styles in a flipped classroom [6]. The flexibility in employing a suitable learning style when joining a flipped classroom may happen as the learning process occurs in a class and in advance through the pre-class activities. In the pre-class activities, the students did some activities, and they control their learning. So, they could accomplish the activities and understand the materials in their way. In the in-class activities, the teachers had more time to apply various teaching techniques. Therefore, it opens more significant opportunities for different students to do their favorite activities. 


\subsubsection{Facilitating discussion}

The interview results showed that implementing a flipped classroom could facilitate discussions among peers and the teacher. Bella explained, "Our difficulties can be prepared to be questioned directly to the lecturer." The excerpt showed that the flipped classroom encouraged self-learning before the in-class learning might trigger some questions the participants could ask the teacher when they met in class. Thus, it could finally encourage discussion between the teacher and the students. Besides encouraging teacher and students' discussion, the flipped classroom could also enable peer sharing. Cindy asserted, "We can exchange what the understanding and idea with friends about the material given by the lecturer."

Similarly, Andrew said, "If there is no I know, I can also discuss with my friends." Students can share ideas and opinions on the materials they learn previously in the pre-class activities with the flipped classroom. When they have questions or unclear understanding, they can ask their peers.

The findings showed that with the flipped classroom's implementation, the students could share ideas and understanding with their teachers and peers. With pre-class activities, they were required to learn autonomously as the preparation for the in-class meeting. When they had confusion or questions, they had the opportunity to discuss it with their teacher and peers in the in-class session. The discussion became more significant as each member had got background knowledge or prior understanding [7]. The students also expressed that the flipped classroom enabled them to collaborate with their peers. Peers' support can motivate low achievers to participate during group discussion [16] and enable students to interact with students during the teaching and learning process [17]. With the background knowledge they had, they could exchange the understanding they had with their peers. In his study, Tucker also found that flipped classrooms could facilitate collaborative learning among students [2].

\subsubsection{Increasing students' readiness}

The participants reported that learning in a flipped classroom helped them prepare for their learning. Bella explained that "We have prepared the materials. So, we do not only know the materials, we also have got the bigger picture". Cindy also added that "We have mastered the materials, so in the classroom, we can practice." Cindy and Bella perceived that the flipped classroom made them ready for learning as they had started learning in the pre-class activities. They watched video lectures and learned materials based on the resources uploaded in the learning management system. With these activities, they had built background knowledge of the materials they would learn in the in-class activities. Therefore, when they were in the in-class session, they felt more ready to learn as they got a picture of the materials discussed in class. Aşıksoy and Özdamlı also found that learning under a flipped classroom made students feel more confident since they had learned the materials in advance [7]. With readiness students had, they could also be prepared and engaged in the in-class activities

\subsection{Difficulties Students Faced in Joining Flipped Classroom}

The interviews results showed that the participants underwent some difficulties when attending a course applying the flipped classroom. The difficulties were grouped into two main themes, i.e., inability to manage learning and technical problems.

\subsubsection{Inability to learning management}

One problem the participants faced dealt with their focus on learning. Bella said, "Even though we are focused, sometimes we think about I haven't washed my clothes, I haven't washed my dishes yet." Also, Andrew stated, "Sometimes it is often delayed, so students focus more on other things than on assignments." The two excerpts indicated that Bella and Andrew were distracted when learning in a flipped classroom. Rather than learning autonomously in the pre-class activities, they tended to pay more attention to other errands. Besides getting distracted by other errands, Bella also confessed that she tended to procrastinate her learning. She asserted, "It is difficult to arrange the time to focus on studying the material and then delay it." Similarly, Dara confessed that she procrastinated her learning in a flipped classroom. She stated, "I usually don't open it immediately depending on the deadline."

The results indicated that the students had difficulties maintaining focus when they were learning in a flipped classroom. One component which marks the success of learning under a flipped classroom is students' ability to manage their learning. The students' ability to maintain focus can hamper their learning. The students reported that they got easily distracted to do other errands instead of learning. They also tended to procrastinate their learning. Distractions and procrastination can be a common problem in a flipped classroom since the students needed to manage their learning, particularly in the pre-class and post-class activities. Without supervision from the teacher and a specific schedule, the students can get easily distracted and inhibit their learning. This finding is in line with Sekar, who emphasized that students could postpone their learning in a flipped classroom as they control their learning and that no one is assisting or supervising their learning [12].

\subsubsection{Poor peer collaboration}

The in-class learning in the flipped classroom model, which emphasized active collaboration and active learning, was reported as a challenge by the participants. They expressed difficulties in cooperating with their peers. Andrew stated, "My groupmates sometimes did not help [the group task]." Bella also said, "There are members who don't participate in solving the problem." Their lacked participation may be caused by their lacked understanding of the background knowledge. Thus, they could not contribute to the group task. Dara added, "They have not mastered the materials, so they lack opinions on the materials." 
The interview excerpts showed that active learning through discussions in the flipped classroom became a challenge for them. With the expectation that every member could actively participate in accomplishing the group tasks, some members did not optimally contribute to the tasks. This challenge may happen since the flipped classroom encouraged the students to work in a team, while students preferred individual learning. This discrepancy in the characteristics of the learners can lead to ineffective collaboration among students. This finding corroborated with a study that found that students who were not into active learning and collaborative learning might face challenges when learning in a flipped classroom [13]. The challenge can also happen in the flipped classroom; the students were encouraged to do some pre-class activities. Their understanding of these activities was crucial as it would be background knowledge for the in-class activities. Thus, students who did not do the pre-class activities might not get a basic understanding, which eventually hampered their inclass learning.

\subsubsection{Technical problems}

One common problem which emerged in blended learning, i.e., technical problem, also emerged in the interview. Cindy stated that the difficulty in joining a flipped classroom was due to poor internet connection. She pointed out, "When the boarding house's wi-fi was slow, it very affects." Another problem the students reported with the implementation of the flipped classroom deals with poor technological support. As the flipped classroom applied blended learning in which the pre-class activities were done online, internet access became a crucial factor supporting learning success. However, the students reported that they had poor internet connection and access, which hampered their learning.

Another problem that emerged from the interview was the video lectures used in the flipped classroom. One of the participants, Exon, said, "If the video is too long, it makes me bored." He explained that learning through a long video was not enjoyable. In the same vein, Andrew pointed out, "If the videos are long, I usually skipped them." Videos with long duration also influenced students' understanding. Cindy reported, "If the videos are long without clear points, I don't understand [the materials from the videos]." The interview excerpts showed that the participants dealt with a technical problem regarding the learning model videos. They experienced watching long duration video lectures, which interfered with their understanding and interests. It finally made them skip watching the videos. It will be an issue when the students skipped watching video lectures. They may lose the opportunity to learn and achieve knowledge. In their study, Bishop and Verleger found that the students preferred materials in videos; however, they disliked videos with long duration [9]. Video lectures should also be kept short [18]. That way, the use of video lectures will be more effective.

\section{CONCLUSION AND IMPLICATIONS}

The present study investigated the first-year English language education students who experienced learning in a flipped classroom for the first time. The students reported that they perceived both benefits and difficulties in learning under a flipped classroom model through in-depth interviews. The students showed that they could learn flexibly in terms of time and places, learning style used, and materials to learn with the learning model. They could adjust their learning to what matched their preferences and needs. Also, they reported that the flipped classroom model facilitated them in a discussion. They had more opportunities to discuss with their teacher and classmates, which enhanced their learning.

At last, they reported that with flipped learning, they felt more ready to learn as they had prepared before the inclass learning. Besides the benefits they perceived, the students also reported difficulties in the implementation of the flipped classroom. They expressed that their inability to manage their learning became an obstacle in learning under a flipped classroom. Besides, collaboration among peers, which was shared on implementing the in-class session, was considered ineffective. Some group mates did not contribute to the accomplishment of the tasks. It eventually impeded the learning process. Finally, as the flipped classroom is a part of blended learning that involves the internet and technology, facilities supporting learning become crucial. The students reported that they had difficulty due to poor internet access and lengthy videos.

The results of the study lead to some implications. With the benefits of the new teaching model, flipped teaching is worth implementing. Creative teaching that puts learners as the center of learning encourages students to participate and be more motivated. [19]. However, for the betterment and more effectiveness of implementing a flipped classroom, teachers' roles should be reconsidered. Although learning in a flipped classroom is more self-directed, not all students can manage their learning. In learning, which puts students in as the center of learning and provides both in-class and outclasses activities, learners' learning autonomy is required [20]. Thus, teachers need to increase students' awareness of the importance of self-directed learning and managing learning. Teachers can train students to manage their learning before flipped learning to ensure that they know what and how to do the learning in a flipped classroom. Teachers can also create activities and tasks with a set schedule to help students manage their learning. That way, they can get the flexibility in learning as well as manage their learning activities. In the in-class activities, teachers' roles in ensuring that collaboration among students can work effectively are also imperative. Teachers should create tasks and activities which can encourage each groupmate to be responsible for their tasks. Teachers should also ensure that all students have learned and done the pre-class activities to prepare collaborative work in in-class activities. Another implication is regarding the facilities. For the effectiveness of a flipped classroom, ensuring that all students are equipped with facilities that support their learning under a flipped classroom is essential. Schools or institutions can provide facilities that can help students access materials freely and easily. Video lectures should also be created as concisely as possible to minimize technology and internet access problems. 


\section{REFERENCES}

[1] H. Staker and M. B. Horn, "Classifying K-12 blended learning." 2012. [Online]. Available: https://eric.ed.gov/?id=ED535180

[2] B. Tucker, "The flipped classroom," Education Next, vol. 12, no. 1, pp. 82-83, 2012

[3] C. F. Herreid and N.A Schiller, "Case studies and the flipped classroom," Journal of College Science Teaching, vol. 42 , no. 5, pp. 62-66, 2013.

[4] K. McDonald and C. M. Smith, "The flipped classroom for professional development: Part I. Benefits and strategies," The Journal of Continuing Education in Nursing, vol. 44, no. 10, pp. 437-438, 2013.

[5] A. Roehl, S. L. Reddy, G. J. Shannon, "The flipped classroom: An opportunity to engage millennial students through active learning strategies,"Journal of Family \& Consumer Sciences, vol. 105, no. 2, pp. 44-49, 2013.

[6] J. Strayer, "The effects of the classroom flip on the learning environment: A comparison of learning activity in a traditional classroom and a flip classroom that used an intelligent tutoring system," unpublished.

[7] G. Aşıksoy and F. Özdamlı, "Flipped classroom adapted to the ARCS model of motivation and applied to a Physic course," Eurasia Journal of Mathematics, Sciences \& Technology Education, vol. 12, no. 6, pp. 1589-1603, 2016.

[8] Z. Zainuddin and S. H. Halili, "Flipped classroom research and trends from different fields of study," International Review of Research in Open and Distributed Learning, vol. 17, no. 3, pp. 313-340, 2016.

[9] J. L. Bishop and M. A. Verleger, "The flipped classroom: A survey of the research," in ASEE national conference, 2013, pp. 1-18

[10] J. E. McLaughlin, P. J. White, J. Khanova, E. Yuriev, "Flipped classroom implementation: A case report of two higher education institutions in the United States and Australia," Computers in the Schools, vol. 33, no. 1, pp. 24-37, 2016.
[11] J. McCarthy, "Reflections on a flipped classroom in firstyear higher education," Issues in Educational Research, vol. 26, no. 2, pp. 332-350, 2016.

[12] J. J. Sekar, "Blended Learning vs. Flipped Classroom: Strength and Challenges," 2019. Accessed: November 28, 2019. [Online]. Available: https://www.researchgate.net/publication/337154969_B1 ended_Learning_vs_Flipped_Classroom_Strengths_and Weaknesses

[13] T. Long, J. Cummins, M. Waugh, "Use of the flipped classroom instructional model in higher education: Instructors' perspectives," Journal of Computing in Higher Education, vol. 29, no. 2, pp. 179-200, 2017.

[14] M. Q. Patton, "Qualitative Research," in Encyclopedia of Statistics in Behavioral Science, 2005, pp. 1633-1636

[15] L. Cohen, L. Manion, and K. Morrison, Research in education (7th ed.). Routledge: London, 2011

[16] T. M. Ardianti, "The role of teacher and peer in helping the students orally participate in an EFL classroom," Journal of Foreign Language Teaching and Learning, vol. 2, no. 2, pp. 38-53, 2017. DOI: https://doi.org/10.18196/ftl.2222

[17] E. Puspitasari, "Classroom activities in content and language integrated learning," Journal of Foreign Language Teaching and Learning, vol. 1, no. 2, pp. 1-13, 2016. DOI: https://doi.org/10.18196/ftl.129

[18] T. Long, J. Logan, M. Waugh, "Students' perceptions of the value of using videos as a pre-class learning experience in the flipped classroom," TechTrends, vol. 60, no. 3, pp. 245-252, 2016.

[19] A. Kakar, K. Sarwari, M. Miri, "Creative teaching in EFL classrooms: Voices from Afghanistan," Journal of Foreign Language Teaching and Learning, vol. 5, no. 2, pp. 155-171,

[20] N. Lutfi, "The integration of MALL to enhance students speaking skill: An autonomous learning model," Journal of Foreign Language Teaching and Learning, vol. 5, no. 1, pp. 1-19, 2020. DOI: https://doi.org/10.18196/ftl.5144 